\title{
A New Technique of Cogging Torque Suppression in Direct-Drive Permanent Magnet Brushless Machines
}

\author{
W. Fei, and P. C. K. Luk, Senior Member, IEEE
}

\begin{abstract}
In direct-drive electric propulsion systems, where there is no reduction gear to minimize and absorb the adverse effects due to cogging torque generated by the permanent magnet (PM) machine, minimization of cogging torque generation is of particular importance. In this paper, a novel axial pole pairing method is proposed to minimize cogging torque generation in a special three-phase outer-rotor PM brushless machine, which uses uneven stator poles to enhance back electromotive force (EMF). Analytical formulas of the machine's cogging torque are first derived. The new technique is compared with conventional cogging torque suppression methods by means of analytical models and comprehensive finite element analysis (FEA). The FEA results show that the new method not only achieves effective cogging torque reduction, but also results in improved harmonic content of the back EMF. The validity of the FEA model is verified by experimental results from the prototype machines. Finally, the significance of optimizing both the load-independent machine design techniques and load-dependent driving techniques to achieve overall torque ripple minimization is discussed.
\end{abstract}

Index Terms-Axial pole pairing, cogging torque, finite element, magnet pole-arc width, permanent magnet brushless machine, stator teeth pairing, stepped rotor skewing.

\section{INTRODUCTION}

$\mathrm{D}$ ERECT-DRIVES, in which there is no reduction gear for speed and torque conversions, are increasingly popular in electric propulsion applications due to their many benefits such as lower component count, less maintenance, reduced mechanical losses and noises. However, the high strength permanent magnet (PM) used in these direct-drives, while capable of generating remarkably high torque at low speed to make direct-drive possible in the first place, also adds to the undesirable effects of high cogging torque in the motor. Moreover the undesirable effects of cogging torque are unabated in direct-drives as there is no reduction gear. Minimization of cogging torque generation is therefore of particular importance. Analytical studies of cogging torque prediction in surface mounted PM machines are well documented [1]-[6], and various methods of cogging torque reduction based on different models have been comprehensively analyzed [7]-[19]. Nevertheless, it is noteworthy that each approach has its own limitations, and some are far more difficult to implement than others. For

Manuscript received October 9, 2009

The authors are with Power and Drive Systems Group, Department of Engineering Systems and Management, Cranfield University, Shrivenham, SN6 8LA, U. K. (e-mail: w.fei@cranfield.ac.uk; p.c.k.luk@cranfield.ac.uk) example, although skewing stator slots one-slot pitch can virtually eliminate all cogging torque [2], this approach will be difficult to implement in practice with standard winding machines. Alternatively, uniformly skewed rotor magnets can be employed with similar results. However, skewed magnets are very difficult to position and align properly. Moreover, identification of incorrectly assembled rotors can be particularly arduous as the back EMF of an incorrectly assembled rotor may not vary sufficiently from that of a properly assembled rotor to signify an incorrect assembly of magnets. Stepped skewing the rotor is an alternative technique to ease the construction and assembly of the rotor, and can effectively suppress cogging torque generation [8], [9]. Cogging torque can also be significantly reduced by optimal selection of slot and pole combinations [7], stator tooth width and rotor magnet spacing [7], [8], [10]- [13]. Less common yet ingenious measures such as stator teeth pairing [13], stator slot pairing [15], teeth notching [8], [12], [16], [17], magnet pairing [8], magnet segmentation [18], and magnet shifting [8], [19], have also been proposed. From these studies, it can be concluded that suppression of cogging torque invariably leads to some degree of compromise in the performance of the machine, as well as cost penalties in implementation.

In this paper, the minimization of cogging torque of a direct-drive system using a special outer-rotor surface mounted PM brushless machine is investigated. The analytical model of the PM machine, which uses asymmetric stator teeth to enhance the back EMF, is developed using the method of superposition. Cogging torque minimization techniques of stator teeth pairing, optimal magnet pole-arc width, and stepped rotor skewing, are then applied and studied. A new cogging torque suppression method, called axial pole pairing, is proposed. Compared to the conventional circumferential pole pairing technique, the new method still keeps the machine symmetry, and hence allows parallel connection of the coils in each phase. Importantly, there is no imbalance in radial magnetic forces to cause de-centering vibrations. Moreover, this technique not only achieves cogging torque reduction effectively, but also results in an essentially sinusoidal back EMF that facilitates further torque ripple reduction in an $\mathrm{AC}$ mode drive. Besides, there is potential cost saving due to reduced use of magnet material. Both the analytical and FEA results are employed to verify the proposed technique. Finally, the validity of the analytical and FEA models is confirmed by the experimental results from the prototype machines. 


\section{COMPUtATion OF COGging Torque}

Generally, there are two distinct approaches to predict cogging torque: the analytical and numerical ones. The analytical approaches are suitable for relatively simple geometry, but may lead to inaccuracy due to oversimplification Nonetheless, analytical methods provide closed form solutions that can facilitate insightful performance predictions with confidence, which make them ideally suited for preliminary design. On the contrary, the numerical measures, which are normally realized by 2-D and 3-D FEA methods, offer more accurate assessments for even complex geometry. However, FEA methods are usually computationally intensive, and will become extremely time-consuming for optimization involving numerous repetitive computations. Thus, it is instructive to consider analytical and numerical methods as complementary design tools. Typically, analytical methods are used to determine a feasible range for the design parameters, and FEA is used to verify the analytical results and final design optimization where necessary.

\section{A. Analytical Expression of Cogging Torque}

There are three basic ways to analytically predict the cogging torque, a) integration of the lateral forces along the slot sides [1], [4], b) derivative of the air gap co-energy [3], and c) integration of the tangential component of Maxwell stress tensor along a circular contour inside the air gap [5], [6]. Due to its simplicity and reasonable accuracy, the first approach is chosen. Based on typical assumptions [1], the cogging torque can be formulated as the net lateral force acting on the stator teeth, which can be achieved in three stages. First, the air gap flux density distribution of the ideal slotless machine is derived. Then the simplified air gap permeance responsible for slot opening effect is deduced to modify the air gap flux density. Finally, the cogging torque is computed by synthesizing the torque developed by each single slot.

The machine under study uses PMs with parallel magnetization. Hence, the flux density at the surface of the stator bore for an ideal slotless configuration can be expressed as

$$
B_{R s}(\theta)=\sum_{n=1,3,5 \ldots}^{\infty} 2 K_{B}(n)\left(\frac{R_{s}}{R_{m}}\right)^{n p-1} \cos (n p \theta)
$$

where $K_{B}(n)$ can be found in [20], $R_{s}$ and $R_{m}$ are the machine stator outer radius and magnet inner radius respectively, and $p$ is the number of pole pairs. The slot opening effect is taken into account by means of the relative permeance, and the relative permeance in slot area is derived as

$$
\lambda_{r}=\frac{R_{m}-R_{s}+\left(R_{r}-R_{m}\right) / \mu_{r}}{R_{m}-R_{s}+\pi R_{s} \theta_{p} / 2+\left(R_{r}-R_{m}\right) / \mu_{r}}
$$

where $R_{r}$ is magnet outer radius, $\mu_{r}$ is the magnet the relative recoil permeability, and $\theta_{p}$ is the angle between the calculated position and its closest slot side. This equation is only valid for the region $\theta_{p} \leq h_{t t} / R_{s}$, and $\lambda_{r}$ turns to zero when $\theta_{p}>h_{t l} / R_{s}$, where $h_{t t}$ is the height of a tooth tip. Outside the slots, $\lambda_{r}$ keeps unchanged as unity. The slots are normally equally distributed along the stator bore in PM machines. Thus, by synthesizing the torques generated in all the slots, the cogging torque at any rotor position can be derived as

$$
\begin{array}{r}
T_{c}(\theta)=\frac{1}{2 \mu_{0}} \sum_{k=1}^{N_{s}} \int_{0}^{\frac{\theta_{s}}{2}}\left\{R _ { s } ^ { 2 } l _ { s } ( 1 - \theta _ { p } ) \lambda _ { r } ^ { 2 } \left[B_{R s}^{2}\left(\theta+\theta_{p}+\frac{2 k \pi}{N_{s}}\right)\right.\right. \\
\left.\left.-B_{R s}^{2}\left(\theta-\theta_{p}+\theta_{s}+\frac{2 k \pi}{N_{s}}\right)\right]\right\} d \theta_{p}
\end{array}
$$

where $N_{s}$ and $\theta_{s}$ are the number of machine slots and machine slot opening angle span respectively.

\section{B. Finite Element Prediction of Cogging Torque}

FEA is now used routinely for machine performance assessment due to advances in development tools. Cogging torque prediction based on FEA requires accurate field solutions, and hence a large number of meshes. The Maxwell Stress method and the virtual work and energy methods are widely employed by FEA software to calculate electro-magnetic force and torque [21]. In this study, the FEA software JMAG-Studio 9.0 is used to predict the electromagnetic performance of the machine. Specifically, the software employs an efficient method called Nodal Force method (NFM) as the framework of finite elements [22]. Cogging torque is computed by means of NFM in this work.

\section{OUtER-Rotor PM BRUShLESS MAChINE}

Fractional-slot configurations, which are normally facilitated by concentrated coils with shortened end windings to achieve high efficiency and compactness, have become popular in many direct-drive applications. Fig. 1 shows the cross-section and the open-circuit field distribution of the fractional-slot PM brushless machine under study, which has 40 magnet poles on the rotor, and 48 unequal stator poles. Fig. 2 is an exploded view of the machine, which shows the design adopts a simple and effective open-frame configuration for heat dissipation arising from high current density in the windings. The machine uses $0.2 \mathrm{~mm}$ Nippon Steel 20HTH1500 laminated sheets to minimize core losses arising from high electrical frequency developed, and employs high strength parallel magnetized rare earth neodymium-iron-boron ( $\mathrm{NdFe} 35 \mathrm{SH}$ ) permanent magnets mounted on the inner surface of the back iron ring to achieve high torque density. The single-layer concentrated coils are positioned in the wider stator poles to achieve high fill factor and flux linkage. Consequently, each phase winding comprises eight identical stator coils connected in parallel. As such the coils are physically isolated from one another by the narrower stator poles. Thus, mutual inductance is small and good fault tolerance is achieved. The key design parameters of the machine are given in Table I. 

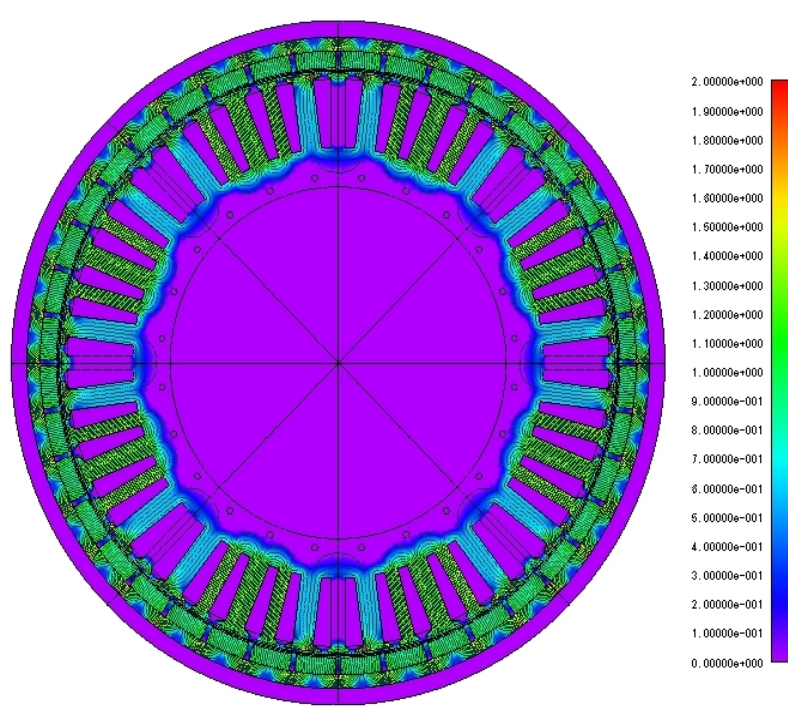

Fig. 1. Open-circuit magnetic field distribution of the proposed machine.

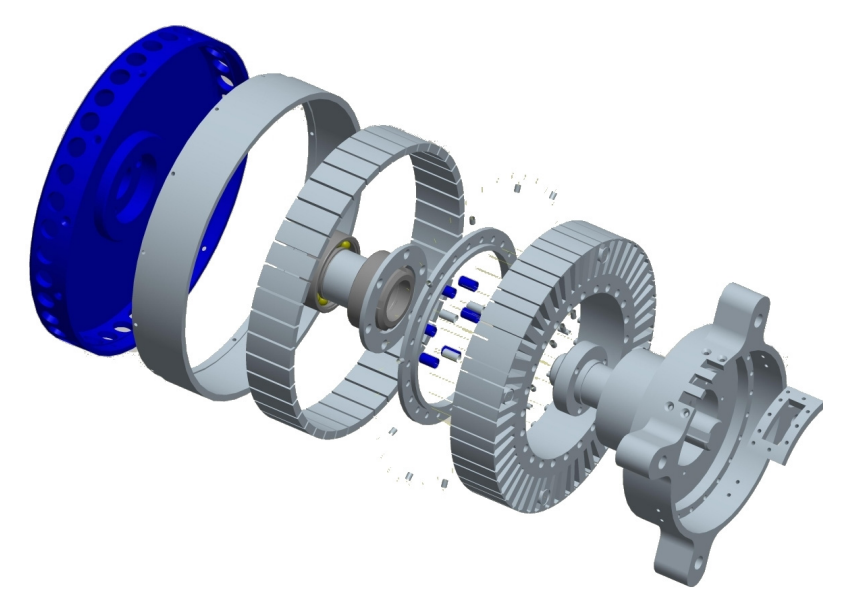

Fig. 2. Exploded view of the proposed machine

TABLE I

DESIGN PARAMETERS OF THE MACHINE

\begin{tabular}{lc}
\hline \hline \multicolumn{1}{c}{ Parameters } & Values \\
\hline Number of phases & 3 \\
DC power supply & $50 \mathrm{~V}$ \\
Rated power output & $6000 \mathrm{~W}$ \\
Rated rotational speed & $2000 \mathrm{rpm}$ \\
Number of magnet poles & 40 \\
Number of stator slots & 48 \\
Rotor outer diameter & $189 \mathrm{~mm}$ \\
Rotor inner diameter & $181 \mathrm{~mm}$ \\
Magnet thickness & $5 \mathrm{~mm}$ \\
Magnet span angle & $8 \mathrm{degree}$ \\
Air gap length & $1.5 \mathrm{~mm}$ \\
Slot opening width & $2 \mathrm{~mm}$ \\
Stator tooth width & $6.18 \mathrm{~mm}$ and $4.1 \mathrm{~mm}$ (uneven) \\
Stator tooth shoe span & $11.55 \mathrm{~mm}$ and $6.43 \mathrm{~mm}$ (uneven) \\
Slot depth & $20 \mathrm{~mm}$ \\
Axial length & $30 \mathrm{~mm}$ \\
Number of turns per coil & 25 \\
Magnet material & NdFe35SH \\
Stator core material & $20 \mathrm{THT} 1500$ \\
\hline \hline
\end{tabular}

Although the stator poles are uneven as seen in Fig. 1, the machine can be considered as a superposition of two identical motors having equal stator poles displaced by a certain angle. Consequently, based on equation (3), the cogging torque can be derived as

$$
\begin{array}{r}
T_{c}(\theta)=\sum_{k=1}^{\frac{N_{s}}{2}} \int_{0}^{\frac{\theta_{s}}{2}}\left\{\frac { R _ { s } ^ { 2 } l _ { s } ( 1 - \theta _ { p } ) \lambda _ { r } ^ { 2 } } { 2 \mu _ { 0 } } \left[B_{R s}^{2}\left(\theta-\theta_{p}-\frac{\theta_{d}}{2}+\theta_{s}+\frac{4 k \pi}{N_{s}}\right)\right.\right. \\
-B_{R s}^{2}\left(\theta+\theta_{p}+\frac{\theta_{d}}{2}+\frac{4 k \pi}{N_{s}}\right)-B_{R s}^{2}\left(\theta+\theta_{p}-\frac{\theta_{d}}{2}+\frac{4 k \pi}{N_{s}}\right) \\
\left.\left.+B_{R s}^{2}\left(\theta-\theta_{p}+\frac{\theta_{d}}{2}+\theta_{s}+\frac{4 k \pi}{N_{s}}\right)\right]\right\} d \theta_{p}
\end{array}
$$

where $\theta_{d}$ is the displacement angle between two sets of equally distributed slots.

\section{STATOR TEETH PAIRING}

In general, cogging torque can be attenuated by reducing the stator slot opening width. However, small stator slot-opening makes the winding process very difficult. Thus the slot-opening width is remained unchanged. From the preceding analytical formulae, the cogging torque of this unequal 48-slot 40-pole machine can be determined by superimposing the cogging torques of two equal 24-slot 40-pole machines displaced with a phase difference. The period of cogging torque for equal stator pole machines can easily be found as $2 \pi / \operatorname{lcm}\left(N_{s}, 2 p\right)$, where $\operatorname{lcm}\left(N_{s}, 2 p\right)$ stands for the lowest common multiple of $N_{s}$ and $2 p$. Thereby, the odd harmonics of the cogging torque can be eliminated if the two terms on the right side of (4) have phase difference as $\pi / \operatorname{lcm}\left(N_{s} / 2,2 p\right)$, whilst the even harmonics, which are normally negligible anyway, will be doubled instead. Minimum cogging torque occurs when displacement angle is

$\theta_{d}=\frac{(2 k+1) \pi}{l c m\left(N_{s} / 2,2 p\right)}, \quad k=0,1,2 \ldots$

With the machine rotor magnet span angle kept at $8^{\circ}$, the peak-to-peak cogging torque values with different displacement angles are computed by analytical and FEA models. The results in Fig. 3 show good agreements between the analytical and FEA results, thus verifying equation (5). The cogging torque profiles from analytical and FEA estimations for some displacement angles are illustrated in Fig. 4. It can be deduced that the cogging torque could be significantly reduced by changing the stator configuration. From equation (5), one can select the displacement angle as $7.5^{\circ}$ or $4.5^{\circ}$ to minimize the cogging torque, as shown in Fig. 3. When the displacement angle is $7.5^{\circ}$, the machine turns equal the machine teeth, and the cogging torque is nearly eliminated with an $8^{\circ}$ magnet span angle. On the other hand, when the displacement angle is $4.5^{\circ}$, cogging torque is much bigger than the theoretical value. As the displacement angle gets smaller, the slots will interact with each other so that equation (2) no longer works any more. 


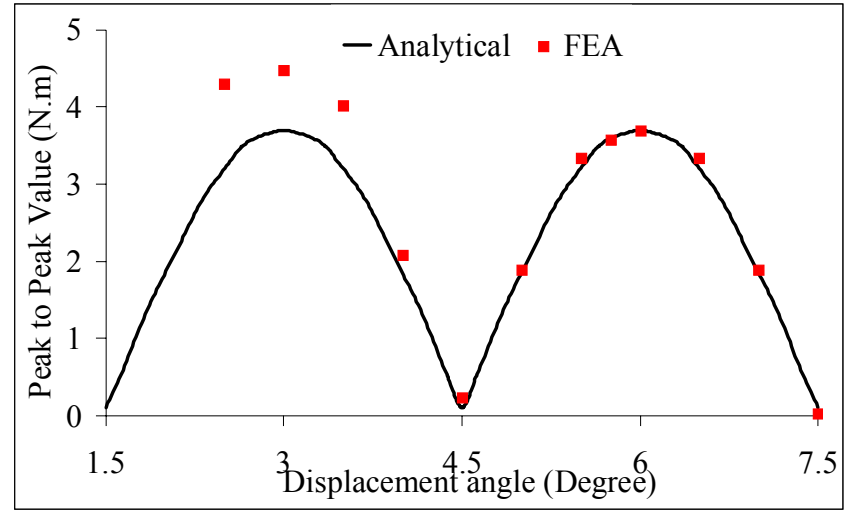

Fig. 3. Peak-to-peak cogging torque values versus displacement angle.

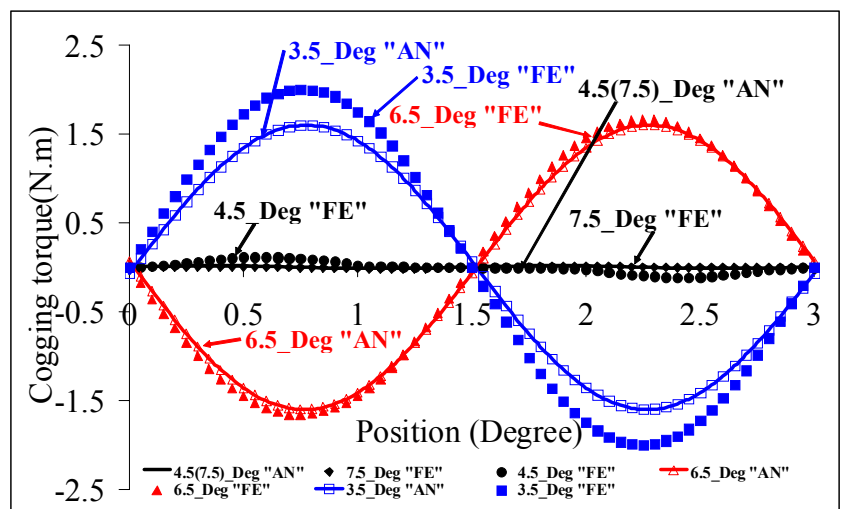

Fig. 4. Cogging torque versus rotor position for different displacement angle ("AN" - Analytical, "FE" - 2D FEA).

Moreover one set of stator poles will become narrow and can easily cause local saturation which brings about inaccuracy in equation (1). Since the analytical model ignores the saturation of the stator core and the influences between the slots, the deviations between the analytical and FEA results will be more prominent as displacement angles get smaller, which is evident by examining both Fig. 3 and Fig. 4. Thus, small displacement angles are not favored in practice as excessive saturation in the stator core would deteriorate machine performance considerably. Here, the stator tooth width is changed in accordance with the displacement angle, which is known as stator teeth pairing technique in the literature [14].

\section{MAgnet Pole-ARC WidTH}

Whilst the rotor magnet pole-arc can greatly influence the magnitude of the cogging torque, an optimum value that minimizes cogging torque is always obtainable. Assuming an ideal air gap flux density distribution and neglecting the fringing effect by the interpole magnets [7], [12], [19], the optimum magnet pole-arc to pole-pitch ratio of the proposed machine can be determined analytically to be 0.667 . However, the actual flux density is not constant over the magnet pole-arc, and is practically zero between the magnet interpoles due to the magnet flux leakage, especially with permanent magnets that are parallel magnetized. Thus the actual optimum magnet pole-arc width is normally higher. From Fig.5, the optimum is

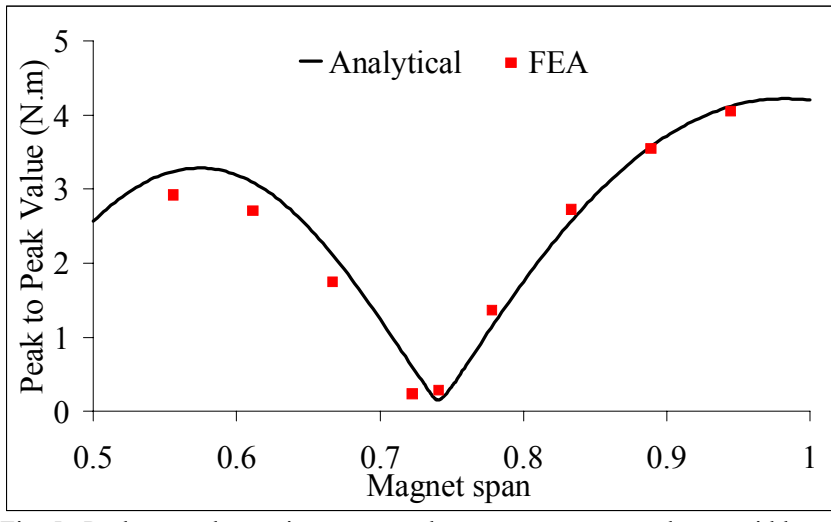

Fig. 5. Peak-to-peak cogging torque values versus magnet pole-arc width.

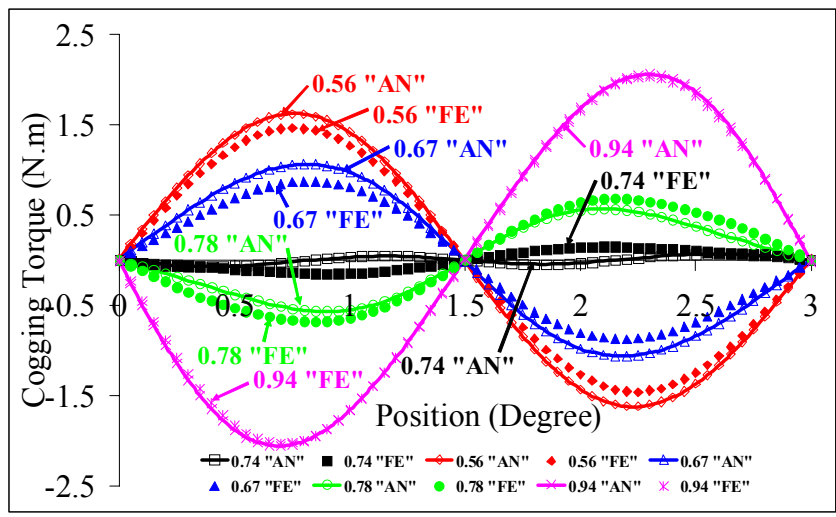

Fig. 6. Cogging torque versus rotor position for different magnet pole-arc width ("AN" - Analytical, "FE" - 2D FEA).

found to be 0.74 both analytically and by FEA, for the existing machine design. Fig. 6 shows the cogging torque waveforms for different magnet pole-arc widths from both analytical and FEA evaluations. Good agreements between the results from analytical model and FEA are achieved. The cogging torque is effectively suppressed by selecting the optimal magnet pole-arc width. However, a relatively small magnet pole-arc would reduce the flux linkage, and hence the average torque output. Consequently, a compromise usually needs to be taken during the machine design stage. Furthermore, as smaller magnet pole-arc widths increase leakage between the permanent magnet and the rotor back iron, the analytical assumption will become less valid. This explains the deviations of the analytical results from the FEA results at small arc widths shown in Fig. 5 and Fig. 6. It is also noted that the existing machine inheres in quite high cogging torque when the magnet pole-arc turns into full-size. Also, it is interesting to point out that the existing magnet pole-arc of 0.89 would turn to an optimum value if the machine approaches the equal teeth configuration, which can be inferred from the results shown in Fig. 3 and Fig. 4.

\section{STEPPED Rotor SKEWING}

Although skew rotor is a well-known method to reduce the cogging torque in surface-mounted PM machines [2], it is not popular in practice due to difficulty in implementation. However, a variant form called stepped rotor skewing [8] or 


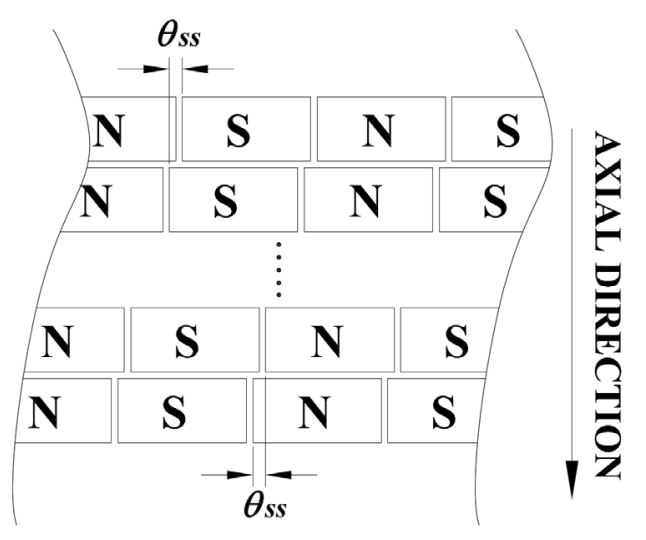

Fig. 7. The stepped rotor skewing topology.

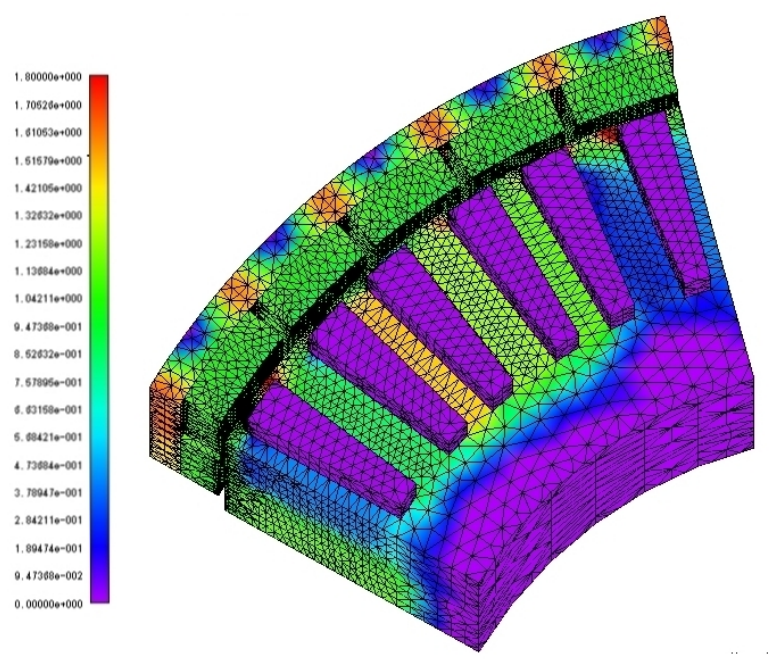

Fig. 8. Flux density distributions of the stepped-magnet machine under no-load condition with 3-D FE meshes.

stepped rotor magnets [9], is more popular as implementation can be made simpler. Fig. 7 shows the method uses discrete steps to skew the permanent magnets axially. If the axial interactions between the magnets are negligible, the cogging torque can be synthesized as

$$
\begin{aligned}
T_{c}(\theta)= & \sum_{i=1}^{N_{s s}} \sum_{k=1}^{N_{s}} \int_{0}^{\frac{\theta_{s}}{2}}\left\{\frac { R _ { s } ^ { 2 } l _ { s } ( 1 - \theta _ { p } ) \lambda _ { r } ^ { 2 } } { 2 \mu _ { 0 } N _ { s s } } \left[B_{R s}^{2}\left(\theta+\theta_{p}+i \theta_{s s}+\frac{2 k \pi}{N_{s}}\right)\right.\right. \\
& \left.\left.-B_{R s}^{2}\left(\theta-\theta_{p}+\theta_{s}+i \theta_{s s}+\frac{2 k \pi}{N_{s}}\right)\right]\right\} d \theta_{p}
\end{aligned}
$$

where $N_{s s}$ is the number of discrete steps, and $\theta_{s s}$ is the mechanical skew angle between the two modules, and the optimal value of which can be given as

$\theta_{s s}=\frac{2 k \pi}{N_{s s} l c m\left(N_{s} / 2,2 p\right)}, \quad k=1,2,3 \ldots$

Normally, $k$ is chosen as unity so that the machine performance

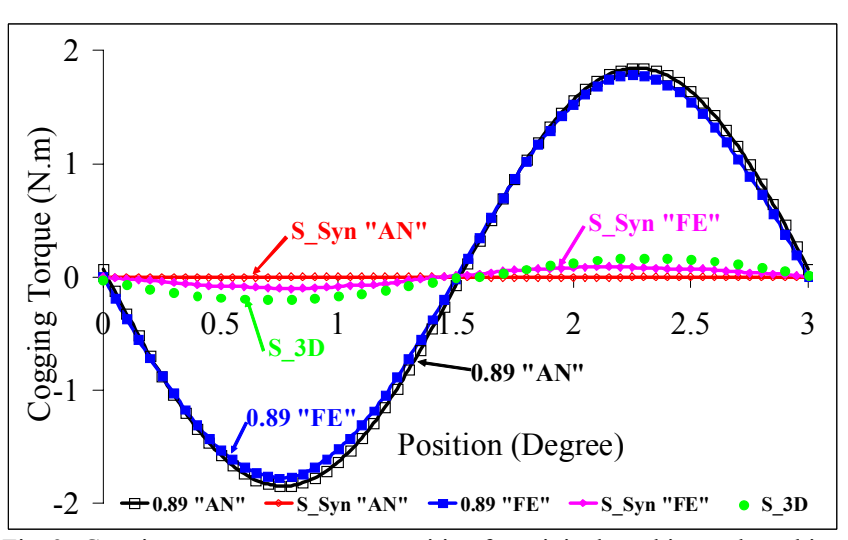

Fig. 9. Cogging torque versus rotor position for original machine and machine with stepped magnets ("AN" - Analytical, "FE" - 2-D FEA, S_Syn synthesized results for stepped magnets, S_3D - 3-D FEA results for stepped magnets).

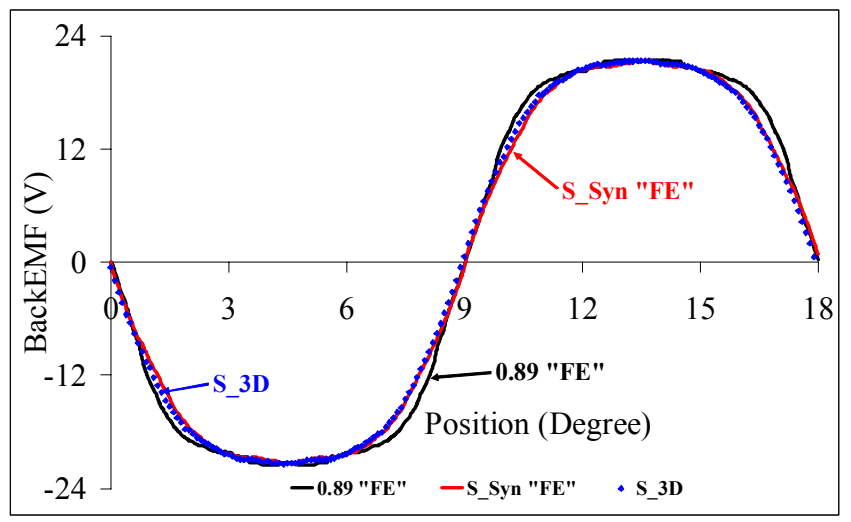

Fig. 10. Phase back EMF versus rotor position for original machine and machine with stepped magnets ("FE" - 2-D FEA, S_Syn - synthesized results for stepped magnets, S_3D - 3-D FEA results for stepped magnets).

will not be compromised beyond an optimal limit. By inspection, it is noted that all the cogging torque harmonics can be eliminated except those multiples of $N_{s s}$ by equally skewing the rotor magnets optimal value from equation (7). From previous analysis, there is almost no even cogging torque harmonics in the existing machine. Consequently, two discrete steps skewed by 1.5 degree are considered adequate. Apart from the analytical and synthesized 2-D FEA results, 3-D FEA is undertaken to model the axial flux interaction and end effects. Only one eighth of the motor is modeled by periodic boundary conditions. Fig. 8 shows the 3-D mesh and no-load flux density distribution of the machine with stepped rotor skewing.

The analytical and FEA cogging torque profiles for the original machine and machine with stepped rotor skewing are shown in Fig. 9, where good agreements between the results are evident. The synthesized results from analytical formula are close to zero, 2-D FEA results are slightly higher, and the 3-D FEA results are highest as a result of the inclusion of the axial interactions and end effects in the model. The phase back EMFs are shown in Fig. 10, which shows the stepped rotor skewing technique slightly reduce the areas of the back EMF trapezoid, and thus the machine performance. It can be concluded that cogging torque can be sufficiently suppressed by stepped rotor 


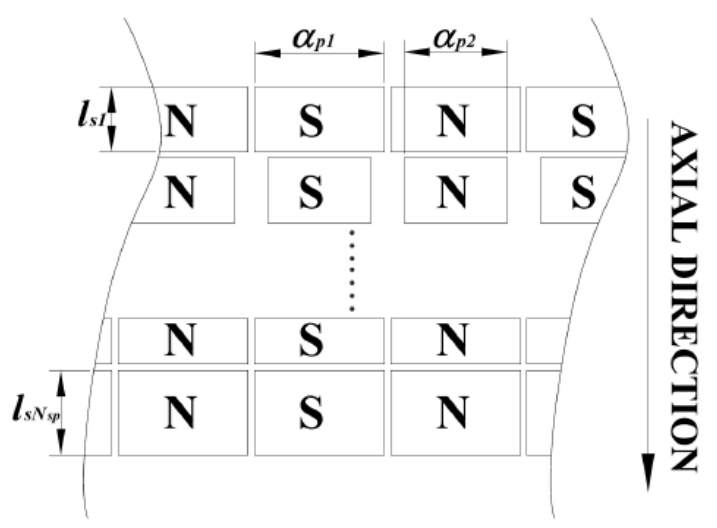

Fig. 11. The axial magnets pairing topology.

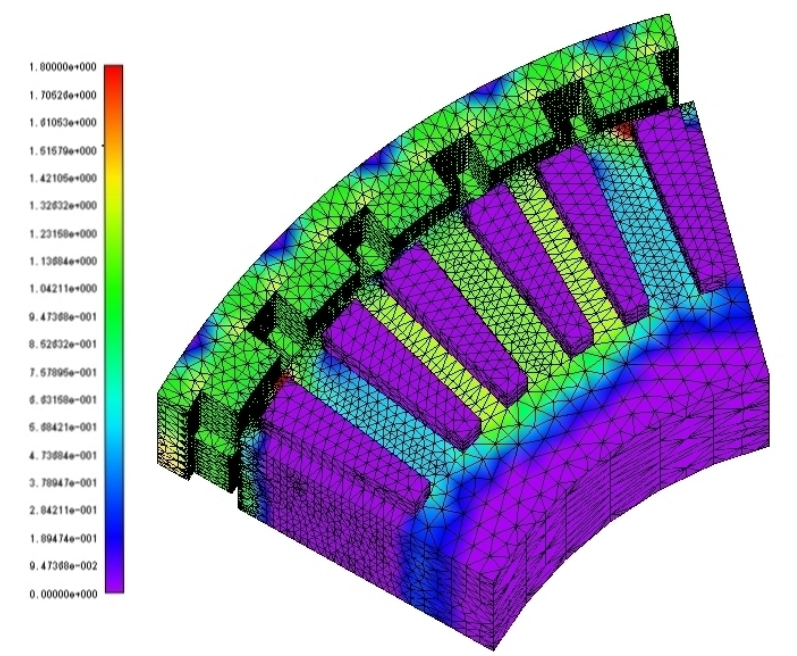

Fig. 12. Flux density distributions of the axial-magnets-pairing machine under no-load condition with 3-D FE meshes.

skewing technique with minimum compromise of performance for the proposed machine.

\section{AXIAL POLE PAIRING}

Implementing circumferential pole pairing artfully can also reduce the cogging torque of PM machines effectively [8]. Since axial flux PM machines present different implementation and manufacture challenges, alternative magnet pole-arc techniques for cogging torque reduction have also been proposed for these machines [23]-[25]. However, with different magnet arc widths, the back EMFs induced in the coils of each pole are different, hence parallel connection of the coils for each phase poses extra challenge in implementation. A new cogging torque reduction technique to facilitate parallel connection of coils, called axial pole pairing, is shown in Fig.11. It should be emphasized that the magnet pairs can comprise different axial lengths as well as different pole-arc widths as illustrated. Similar to conventional circumferential pole pairing, it is always cumbersome to find the proper magnet pole-arc width pairs to reduce cogging torque effectively for the axial pairing technique. An efficient approach to find the

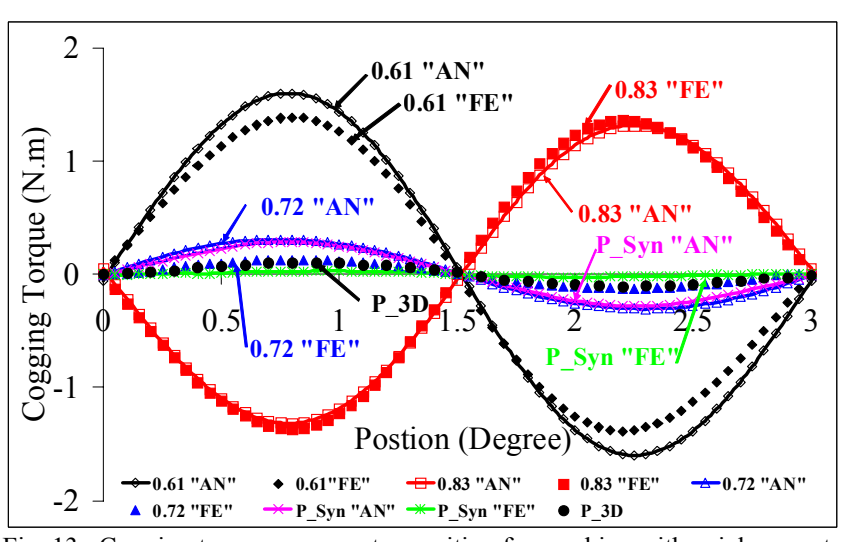

Fig. 13. Cogging torque versus rotor position for machine with axial magnets pairing ("AN" - Analytical, "FE" - 2-D FEA, P_Syn - synthesized results for axial magnet pairing, $P \_3 D-3-D$ FEA results for axial pole pairing).

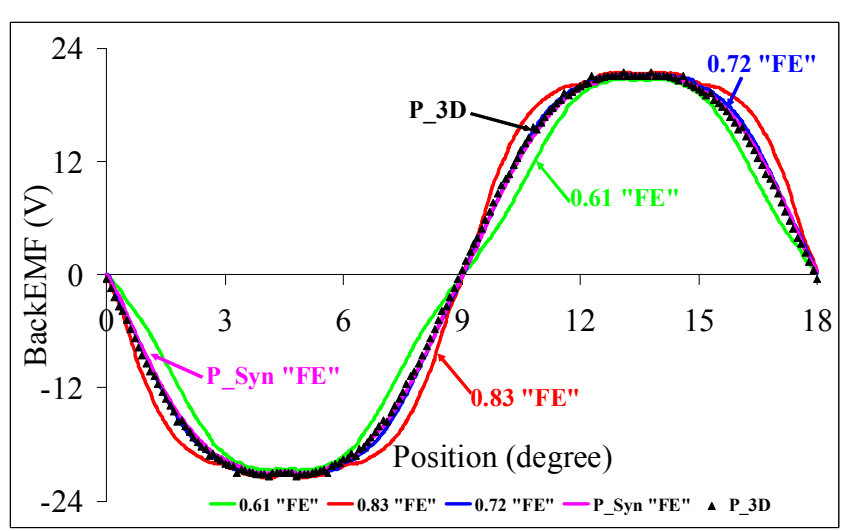

Fig. 14. Phase back EMF versus rotor position for machine wit axial magnets pairing ("AN" - Analytical, "FE" - 2-D FEA, P_Syn - synthesized results for axial magnet pairing, $P \_3 D-3$-D FEA results for axial pole pairing).

proper pairs is therefore highly desirable. The axial pole pairing can be considered as several different-axial-length machines with the same stator configuration axially conjoined together. So the same approach can be taken as in stepped rotor skewing, the cogging torque can therefore be simply derived by synthesizing the corresponding machines assuming negligible axial interactions as

$$
\begin{aligned}
T_{c}(\theta)= & \sum_{i=1}^{N_{s p}} \sum_{k=1}^{N_{s}} \int_{0}^{\frac{\theta_{s}}{2}}\left\{\frac { R _ { s } ^ { 2 } l _ { s i } ( 1 - \theta _ { p } ) \lambda _ { r } ^ { 2 } } { 2 \mu _ { 0 } } \left[B_{R s \alpha p i}^{2}\left(\theta+\theta_{p}+\frac{2 k \pi}{N_{s}}\right)\right.\right. \\
& \left.\left.-B_{R s \alpha p i}^{2}\left(\theta-\theta_{p}+\theta_{s}+\frac{2 k \pi}{N_{s}}\right)\right]\right\} d \theta_{p}
\end{aligned}
$$

where $N_{s p}$ is the number of different pole-arc width magnets, $l_{s i}$ and $B_{R s a p i}(\theta)$ are the axial length and no-load air-gap flux density distributions at the surface of the stator bore with an ideal slotless configuration for $i^{\text {th }}$ magnet set respectively.

Without loss of generality, only one magnet pair with same axial length is considered in this study. From Fig. 5 and Fig. 6, it can be seen that the polarity of the cogging torque of the machine alters when the magnet pole-arc width changes from one side of the optimum 'trough' to the other side. According to 


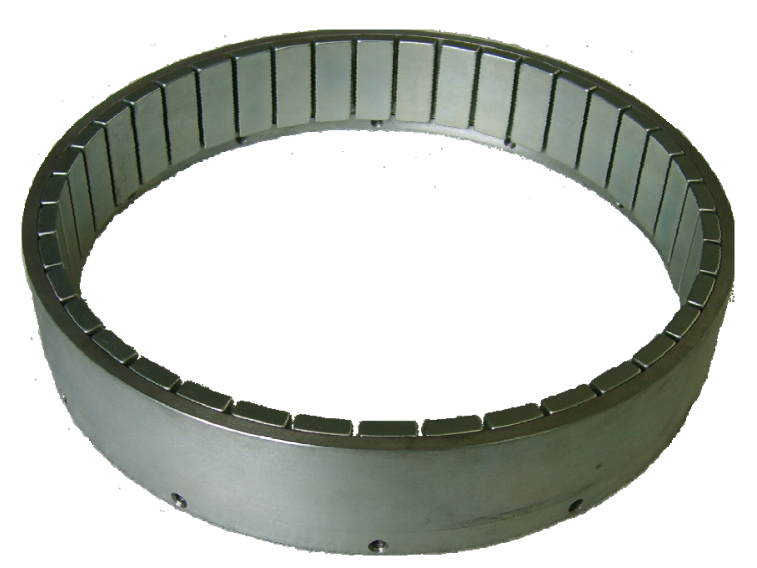

(a) Original rotor with 8-degree pole-arc magnets

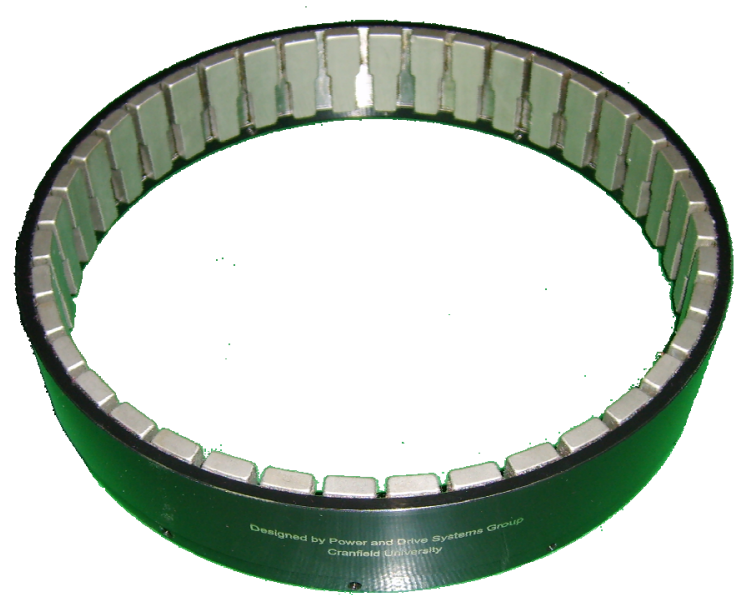

(b) New rotor with proposed axial pole pairing magnets

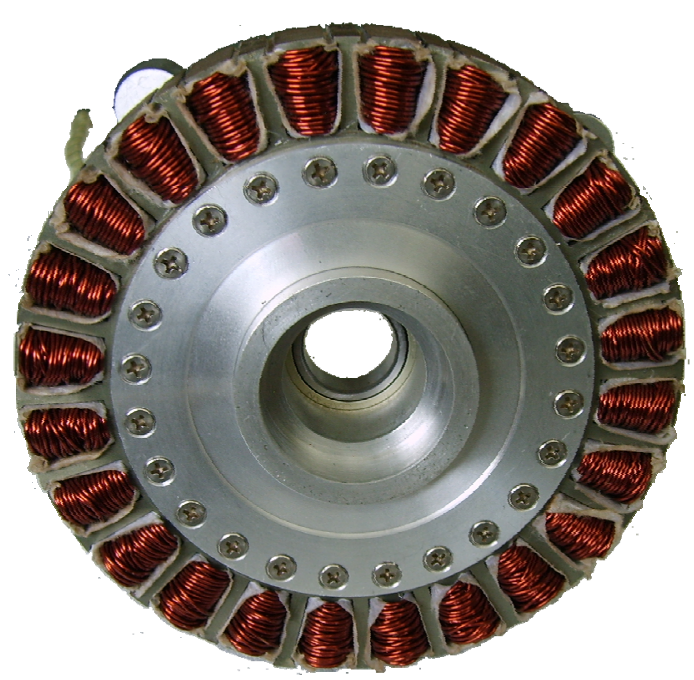

(c) Stator-common for both prototypes

Fig. 15. Rotor and stator of the prototype machines

equation (8), the cogging torque should have different polarities and same peak value for the proper magnet pole-arc

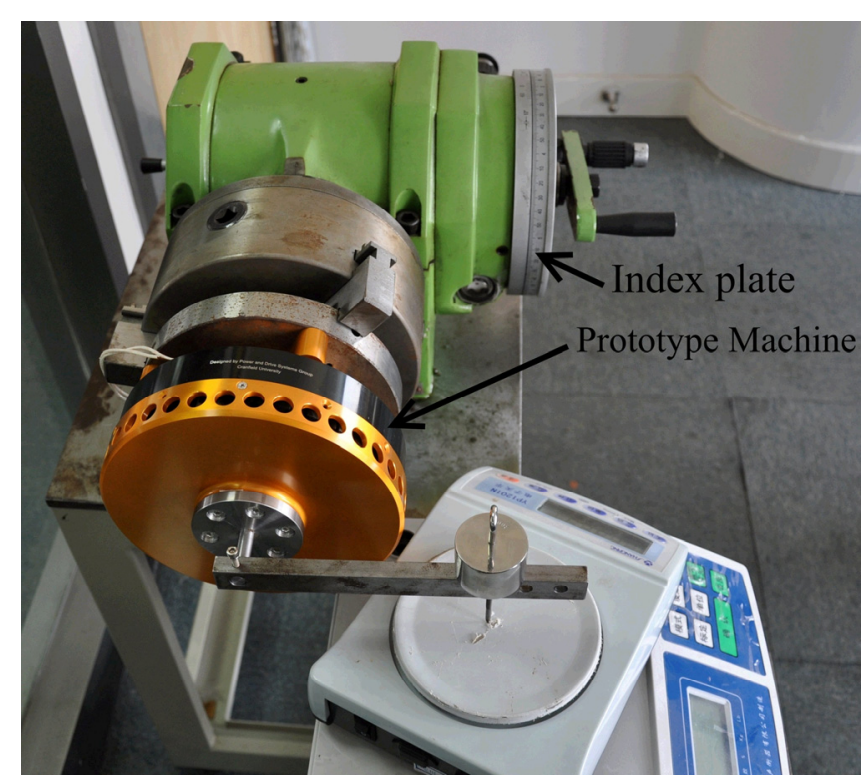

Fig. 16. Experimental setup for cogging torque measurements of the prototype machines.

width pair. Fig. 5 provides a very convenient means to attain the proper pair and to implement the axial pole pairing technique. The pair of $5.5^{\circ}$ and $7.5^{\circ}$ is obtained from Fig. 5 for the proposed machine. Meanwhile the machine with same volume of magnet, $6.5^{\circ}$ magnet pole-arc width, is also studied for comparison. In order to estimate cogging torque more accurately, the axial interactions and end effects are taken into account by using 3-D FEA. Fig. 12 shows the 3-D mesh and no-load flux density distribution of the machine with axial pole pairing.

The analytical and FEA results for the machines are shown in Fig. 13. There is quite considerable discrepancy between the analytical and FEA results, as the superiority of the FEA to model more complex geometry becomes evident. From the FEA results, the average of the pair of 0.72 , which is close to the optimal value discussed in section $\mathrm{V}$, possesses the lowest cogging torque. It can also be seen from the 3D FEA results that the peak cogging torque value from axial pole pairing is about $20 \%$ lower than the normal machine with the same volume of magnet, and about 50\% lower than the stepped magnet configuration. The phase back EMF waveforms are shown in Fig. 14, which shows the axial pole pairing configuration has almost the same back EMF as normal machines with same volume of magnet. Thus, from the FEA results, it can be clearly seen that the proposed axial pole pairing technique is more effective in suppressing cogging torque than the optimal magnet pole-arc width with same volume of magnet, while there is virtually no compromise in the overall performance of the machine. Moreover, it can easily be seen from Fig.11 that the technique can be evolved into a multi-segment multi-layer configuration to reduce eddy current losses and enhance the machine performance. Recently, analytical models based on a simple lumped circuit have been developed to help design and evaluate the advantages of multi-segment multi-layer interior PM machines [26]. Although surface mount PM machines are 


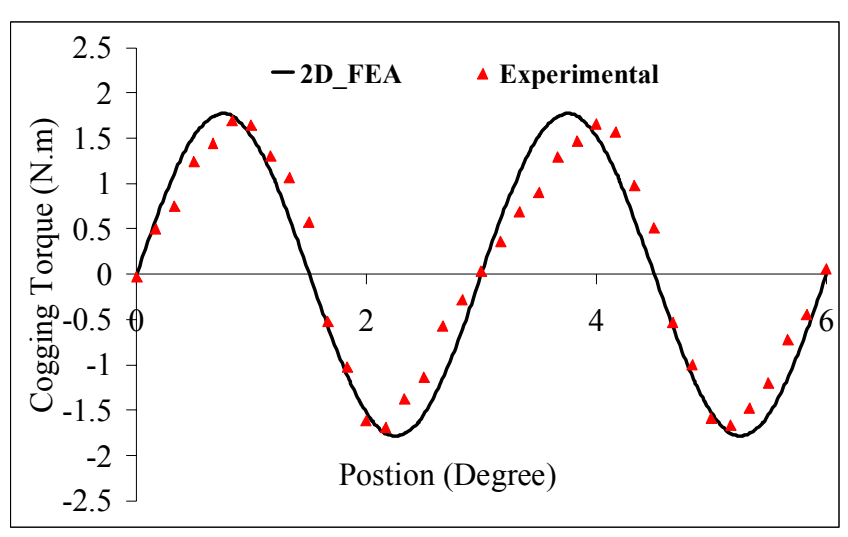

(a) Cogging torque

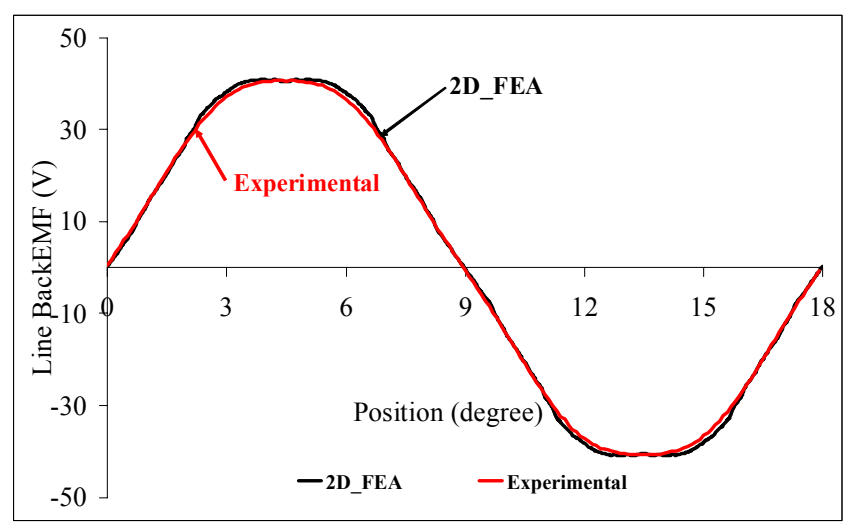

(b) Line back EMF

Fig. 17. Comparison of experimental and FEA results for the original prototype machine.

currently investigated, these analytical models will provide insightful guideline for the future development of the proposed technique, especially for interior PM machines.

\section{EXPERIMENTAL VALIDATION}

Two prototype machines, one based on the original design without cogging torque suppression and one incorporating the axial pole pairing technique, have been built for the validations of the analytical and FEA models, and for verification of the proposed cogging torque suppression method. The pre-assembled prototype machines are shown in Fig. 15. The experimental setup of the cogging torque measurement of the prototype machines is shown in Fig. 16. The rotating index plate is assembled onto the worm-gear unit such that it can turn and hold the stator securely with accurate angular position information. The rotor position was kept stationary during measurements. Two cogging torque periods were generated by the index plate, while 18 samples per period were taken for each machine. For the line back EMF tests, a DC motor was used to drive the rotors of the prototype machines at rated speed.

The experimental test results of the original prototype and the prototype with axial pole pairing are shown in Fig. 17 and Fig. 18 respectively. It can be seen that some deviations exist

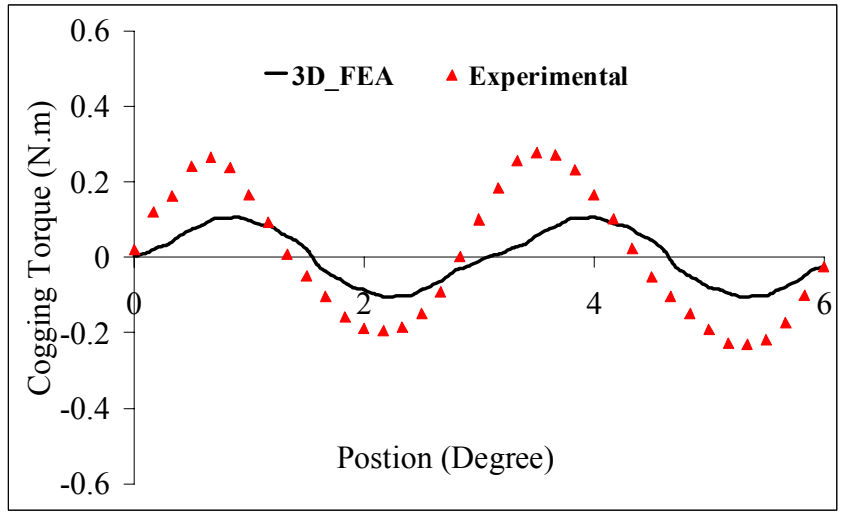

(a) Cogging torque

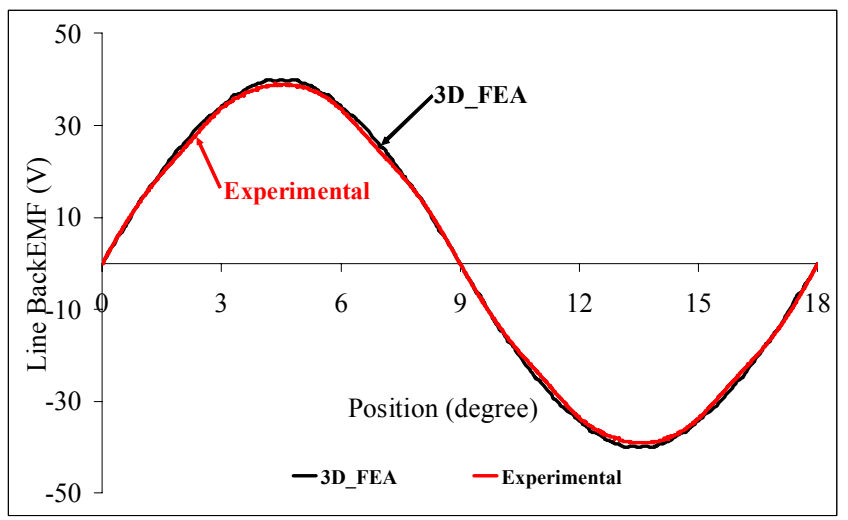

(b) Line back EMF

Fig. 18. Comparison of experimental and FEA results for the prototype machine with axial pole pairing.

between the FEA predicted and measured cogging torque profiles. The deviation is noticeably larger with axial pole pairing as shown in Fig. 18 (a). This may partly be due to the fact that the actual magnetic interactions and flux distribution between the axial pole pair, which have been manufactured and magnetized in one piece, could not be modeled precisely by FEA without detailed information from the manufacturer. Indeed, some information is not available from the manufacturer. In general, cogging torque is very sensitive to the machine parameters. Since the prototype machines have relatively large rotor dimensions and high number of magnet poles, it is particularly challenging to assemble the magnets in position with adequate precision. In addition, there is manufacturing tolerance for the magnets, which may be potentially significant due to the relatively small dimensions of the magnets. Taking these factors in consideration and also errors due to measurement and instrumentation, the cogging torque results are considered highly satisfactory, with reasonably good correlations between the FEA and experimental results. From Fig.17 (a), it can be seen that the cogging torque is $3.6 \mathrm{Nm}$ (peak-to-peak), or nearly $11.5 \%$ of the rated torque, with no suppression technique. This level of cogging torque is likely to cause adverse effects of vibration and noises in a direct-drive application. From Fig.18 (a), the 
cogging torque is reduced to $0.6 \mathrm{Nm}$ (peak-to-peak), or $1.9 \%$ of the rated torque, for the proposed axial pole pairing technique. This significant reduction is equivalent to the effect of using a $6: 1$ reduction gear, and thus verifies the utility of the proposed cogging torque suppression in direct drive applications. For the back EMF tests, it can be seen from Fig. 17 (b) and Fig. 18 (b) that excellent agreements between the FEA and experimental results are found. Voltage measurement is normally less sensitive to manufacturing deficiency and experimental errors than cogging torque measurement. From Fig. 18(b), the back EMF is essentially sinusoidal for the machine with axial pole pairing, whereas Fig. 17(b) shows the back EMF is more trapezoidal for the original machine. However, the maximum values of back EMF are both at about $80 \mathrm{~V}$ (peak-to-peak).

\section{Discussions}

Whereas there is a significant body of literature focusing on load-independent cogging torque reduction techniques, there appears less research effort to incorporate these techniques with load-dependent torque ripple reduction methods to achieve minimum torque ripple of the drive system. In practice, cogging torque suppression techniques should be carefully chosen based on the driving mode of the machine, the average torque and overall torque ripple requirement of the drive. In general, the PM brushless machine can be driven either in brushless AC (BLAC) or brushless DC (BLDC) mode based on the machine's back EMF profile. Although more sophisticated load-dependent torque minimization techniques exist [27], as a general rule of thumb, BLAC mode is used for PM machines with sinusoidal back EMF, and BLDC is preferred for PM machines with trapezoidal back EMF. From the study, stator teeth pairing can effectively mitigate the cogging torque with proper choice of magnet pole-arc width. However, the practical optimal displacement angle would conduce to even teeth configuration for the proposed machine. Together with double layer winding configuration, the back EMF of the machine will become much closer to sinusoidal. Similarly, the optimal magnet pole-arc width technique and the proposed axial pole pairing technique will result in essentially sinusoidal back EMF, as shown in Fig. 14 and Fig. 18. Thus, these methods are particularly suitable for BLAC mode of operation for minimum torque ripple of the drive system, and are recommended for direct-drive applications. On the other hand, the stepped rotor skewing technique could drastically reduce the cogging torque of the proposed machine and still keep the back EMF still almost trapezoidal as shown in Fig. 10. It is thus more suitable for a BLDC mode of operation, where higher torque ripple is inevitable. Thus, for overall system level torque ripple minimization, it is crucial to optimize both the load-independent machine design and driving techniques to be deployed.

\section{CONCLUSIONS}

The cogging torque suppression techniques are investigated for a special outer rotor 3-phase PM brushless machine with an uneven 48-slot 40-pole fractional slot configuration, covering a range of methods from both the stator and rotor perspectives, and involving stator teeth pairing, optimal magnet pole-arc width and stepped rotor skewing. A new technique called axial pole pairing is then proposed. Comprehensive studies are carried out to investigate the new technique and to compare it with existing methods. The study shows that all the methods can indeed reduce cogging torque very effectively. Furthermore, experiments are undertaken to validate the analytical and FEA results, and the proposed axial pole pairing technique. Besides, the guideline on determining the optimal cogging torque suppression techniques are discussed based on the operation mode deployed for the proposed machine.

Although the investigations have been undertaken on an outer rotor PM machine with a specific configuration, it is envisaged the proposed axial pole pairing method can also be applied to other PM machines with different configurations.

\section{ACKNOWLEDGMENT}

The authors gratefully acknowledge Powersys for the software support of JMAG-Studio, Chen Yuan of Wujiang Nanyuan Electrical Co. China for the professional advice on motor design and manufacture, and Scorpion Precision Industry (HK) Co. Ltd for prompt and excellent motor manufacture service.

\section{REFERENCES}

[1] Z. Q. Zhu and D. Howe, "Analytical prediction of the cogging torque in radial-field permanent magnet brushless motors," IEEE Trans. Magn., vol. 28, no. 2, pp. 1371-1374, Mar. 1992.

[2] D. C. Hanselman, "Effect of skew, pole count and slot count on brushless motor radial force, cogging torque and back EMF," IEE Proc. B-Electr. Power Appl., vol. 144, no. 5, pp. 325-330, 1997.

[3] J. F. Gieras, "Analytical approach to cogging torque calculation of PM brushless motors," IEEE Trans. Ind. Appl., vol. 40, no, 5, pp. 1310-1316, Sept./Oct. 2004.

[4] G. Sooriyakumar, R. Perryman, and S. J. Dodds, "Improved cogging torque calculation methods for surface mounted permanent magnet synchronous motors," in Proc. Int. Uni. Power Engineering Conf., vol. 2, pp. 753-757, Sept. 2006.

[5] J. Steinbrink, "Analytical determination of the cogging torque in brushless motor excited by permanent magnets," in Proc. IEEE int. Electric Machine \& Drives Conf., vol. 1, pp. 172-177, May 2007.

[6] D. Zarko, D. Ban, and T. A. Lipo, "Analytical solution for cogging torque in surface permanent-magnet motors using conformal mapping," IEEE Trans. Magn., vol. 44, no. 1, pp. 52-65, Jan. 2008.

[7] L. Zhu, S. Z. Jiang, Z. Q. Zhu, and C. C. Chan, "Analytical methods for minimizing cogging torque in permanent-magnet machines," IEEE Trans. Magn., vol. 45, no. 4, pp. 2023-2031, April 2009.

[8] N. Bianchi and S. Bolognani, "Design techniques for reducing the cogging torque in surface-mounted PM motors," IEEE Trans. Ind. Appl., vol. 38, no, 5, pp. 1259-1265, Sept./Oct. 2002.

[9] Z. Q. Zhu, S. Ruangsinchaiwanich, D. Ishak, and D. Howe, "Analysis of cogging torque in brushless machines having nonuniformly distributed stator slots and stepped rotor magnets," IEEE Trans. Magn., vol. 41, no. 10, pp. 3910-3912, Oct. 2005.

[10] T. Li and G. Slemon, "Reduction of cogging torque in permanent magnet motors," IEEE Trans. Magn., vol. 24, no. 6, pp. 2901-2903, Nov. 1988. 
[11] B. Ackermann, J. H. H. Janssen, R. Sotteck, and R. I. van Steen, "New technique for reducing cogging torque in a class of brushless DC motors," IEE Proc. B-Electr. Power Appl., vol. 139, no. 4, pp. 315-320, 1992.

[12] Z. Q. Zhu and D. Howe, "Influence of design parameters on cogging torque in permanent magnet machines," IEEE Trans. Energy Convers., vol. 15 , no. 4, pp. 407-412, Dec. 2000.

[13] Y. Yang, X. Wang, R. Zhang, T. Ding, and R. Tang, "The optimization of pole-arc coefficient to reduce cogging torque in surface-mounted permanent magnet motors," IEEE Trans. Magn., vol. 42, no. 4, pp. 1135-1138, April 2006.

[14] S. M. Hwang, J. B. Eom, G. B. Hwang, W. B. Jeong, and Y. H. Jung, "Cogging torque and acoustic noise reduction in permanent magnet motors by teeth pairing," IEEE Trans. Magn., vol. 36, no. 5, pp. 3144-3146, Sept. 2000.

[15] Y. Yang, X. Wang, R. Zhang, C. Zhu, and T. Ding, "Research of cogging torque reduction by different slot width pairing permanent magnet motors," in Proc. $8^{\text {th }}$ int. Electric Machines and Systems Conf., vol. 1, pp. 367-370, Sept. 2005.

[16] C. S. Koh and J.-S. Seol, "New cogging torque reduction method for brushless permanent-magnet motors," IEEE Trans. Magn., vol. 39, no. 6, pp. 3503-3506, Nov. 2003.

[17] Y. Yang, X. Wang, X. Leng, D. Wang, and S. Liu, "Reducing cogging torque in surface-mounted permanent magnet motors by teeth notching," in Proc. $2^{\text {nd }}$ IEEE Ind. Eletron. and Appl. Conf., pp. 265-268, May 2007.

[18] R. Lateb, N. Takorabet, and F. Meibody-Tabat, "Effect of magnet segmentation on the cogging torque in surface-mounted permanent-magnet motors," IEEE Trans. Magn., vol. 42, no. 3, pp. 442-445, Mar. 2006.

[19] L. Dosiek and P. Pillay, "Cogging torque reduction in permanent magnet machines," IEEE Trans. Ind. Appl., vol. 43, no, 6, pp. 1565-1571, Nov./ Dec. 2007.

[20] Z. Q. Zhu, D. Howe, and C. C. Chan, "Improved analytical model for predicting the magnetic field distribution in brushless permanent-magnet machines," IEEE Trans. Magn., vol. 38, no. 1, pp. 229-238, Jan. 2002.

[21] D. Howe and Z. Q. Zhu, "The influence of finite element discretisation on the prediction of cogging torque in permanent magnet excited motors," IEEE Trans. Magn., vol. 28, no. 2, pp. 1080-1083, Mar. 1992.

[22] I. Nishiguchi, A. Kameari, and K. Haseyama, "On the local force computation of deformable bodies in magnetic field," IEEE Trans. Magn., vol. 35, no. 3, pp. 1650-1653, Mar. 1999.

[23] M. Aydin, R. Qu, and T. A. Lipo, "Cogging torque minimization technique for multiple-rotor, axial-flux, surface-mounted-PM motors: alternating magnet pole-arcs in facing rotors," in Proc. IEEE Ind. Appl. Soc. Conf., vol. 1, pp. 555-561, Oct. 2003.

[24] M. Aydin, Z. Q. Zhu, T. A. Lipo, and D. Howe, "Minimization of cogging torque in permanent magnet machines: Design concepts," IEEE Trans. Magn., vol. 43, no. 9, pp. 3614-3622, Sept. 2007.

[25] W. Fei and P. C. K. Luk, "Cogging torque reduction techniques for axial-flux surface-mounted permanent-magnet segmented armature torus machines," in Proc. IEEE Int. Symp. Ind. Electron., pp. 485-490, 2008.

[26] L. Zhu, S. Z. Jiang, Z. Q. Zhu, and C. C. Chan, "Analytical Modeling of Open-Circuit Air-Gap Field Distributions in Multisegment and Multilayer Interior Permanent-Magnet Machines," IEEE Trans. Magn., vol.45, no.8, pp.3121-3130, Aug. 2009.

[27] Weizhe Qian Panda, S.K. Jian-Xin Xu, “Torque ripple minimization in PM synchronous motors using iterative learn control," IEEE Trans. Power Electron., vol. 19, no.2, pp.272-279, March 2004. 